\title{
Cera y devoción. Los agnusdei en la colección del Museo Nacional de Antropología
}

\author{
M. ${ }^{a}$ ANTONia Herradón Figueroa \\ Museo Nacional de Antropología. Madrid
}

\section{LA CERA EN LA LITURGIA CATÓlicA}

Hasta el comienzo del siglo $\mathrm{xx}$, la cera, sustancia sólida, moldeable y amarillenta que segregan las abejas para formar las celdillas de los panales, ha sido un producto muy apreciado, y no sólo por parte de las clases sociales más favorecidas, que la prefirieron como fuente de iluminación frente a las grasas animales. También la Iglesia hizo suya esta materia, revistiéndola de un profundo simbolismo, de manera que puede decirse que la cera ha desempeñado un papel fundamental en la liturgia católica desde los primeros tiempos del cristianismo.

En un primer momento es la llama de los cirios de cera, que desprende una luz limpia sin olor ni humo, lo que se considera una representación de Cristo, pero rápidamente el simbolismo de la vela abarcó a la cera y a su blancura. Para San Anselmo ala cera producida por la abeja virgen es el símbolo de la carne de Cristo, nacido de la Virgen María; el pábilo es el símbolo de su alma; la llama, el de su divinidad. Y en ninguna otra criatura se puede encontrar nada mejor que signifique a Cristo" ${ }^{1}$.

La cera, adoptando la forma de velas y cirios, no sólo se ha utilizado para iluminar los altares, sino que ha estado presente en buena parte de los ritos católicos que se desarrollaban a lo largo del año litúrgico (procesiones, fiestas, administración de sacramentos, etc.), acompañando además a los fieles en toda la extensión de su ciclo vital desde el parto al entierro y llegando incluso a sobrepasar en ocasiones la estricta ortodoxia para invadir el terreno de lo que se ha denominado prácticas religiosas paralelas $^{2}$. La acción de encender los cirios ante la imagen de la Virgen

1 Xuaco LÓPEZ ÁLVAREZ, Las abejas, la miel y la cera en la sociedad tradicional asturiana (Oviedo: Real Instituto de Estudios Asturianos, 1994), p. 113.

2 L' abeille, l'bomme, le miel et la cire (Paris: Ministère de la culture. Éditions de la Réunion des musées nationaux, 1981), p. 176. 
o de un santo es, en realidad, una práctica no oficial, aunque ampliamente tolerada, a la que pocas veces aluden los misales u otras obras que dedican páginas a la devoción de los santos. El cirio encendido tiene ante todo una función profiláctica, de intercesión o de agradecimiento, pero por encima de ese uso admitido se le reconocen también ciertos poderes sobrenaturales.

Así, en la Encuesta sobre costumbres de nacimiento, matrimonio y muerte del Ateneo de Madrid (1901-1902) se recogen, por ejemplo, numerosos casos de presencia de velas durante el parto, una práctica que parece haberse desarrollado especialmente en el noreste de España. En la ficha correspondiente a Huesca se informa: "En la habitación donde tiene lugar el alumbramiento, se pone la imagen de la purísima, reliquias de San Ramón y velas que han ardido durante la salve el día de la Purísima o en los monumentos (Jueves Santo) y las que dan el día de las candelas".

Y en la correspondiente a San Sebastián leemos: "En el convento de Carmelitas de esta ciudad proporcionan unas velitas de cera de unos 12 cms., las cuales en su tercio inferior llevan estampada una imagen y adosada a ella una papeleta que contiene unos polvos de composición desconocida (probablemente canela) y juntamente con ellos una tira de papel de unos cuatro milímetros de anchura por diez centímetros de longitud; esta tira está impresa y su texto (casi siempre diferente) es un versículo de la biblia. Las parturientas mandan encender la velita, se toman los polvos y (algunas hasta la envoltura) en la creencia de que terminará el parto antes de llegar la luz a la imagen en la cera estampada" ${ }^{3}$.

También la cera se ha utilizado como ofrenda a la divinidad, al mismo tiempo que se pedía un favor o se manifestaba un agradecimiento por la gracia concedida, bajo la forma de los conocidos exvotos figurati$\operatorname{vos}^{4}$. Velas, cirios y exvotos forman, pues, el conjunto mejor conocido entre todos los objetos fabricados con cera. Sin embargo, junto a estos elementos tan familiares en el ámbito de las prácticas litúrgicas, aparecen

3 Antonio limón Delgado y Eulalia CAStellote Herrero (eds.), El ciclo vital en España (Encuesta del Ateneo de Madrid, 1901-1902), Tomo I, Vol. 1 (Madrid: Museo del Pueblo Español, 1991), pp. 333 y 331 respectivamente.

4 La colección de exvotos del actual Museo Nacional de Antropología ha sido ya estudiada en profundidad por lo que no incidiremos en ella. Sus características y su sentido, así como una amplia documentación gráfica pueden consultarse en Juan Manuel VALADÉS SIERRA, "Una aproximación a los exvotos españoles del Museo Nacional de Antropología”, Anales del Museo Nacional de Antropologia, 3 (1996), pp. 211-233; "Exvotos, un patrimonio peculiar en peligro de extinción", Revista de Arqueología, XVII, 187 (1996), pp. 56-61. 
otros - también fabricados con esta sustancia- que no parecen haber corrido la misma suerte, muy probablemente por haber sido eclipsados por otros elementos litúrgicos o devocionales más espectaculares.

El objetivo de estas líneas es sacar a la luz una parte de "esos otros objetos" fabricados en cera, que forman parte de las colecciones del Museo Nacional de Antropología. Se trata del conjunto de Agnusdei, unas pequeñas tablillas de cera, de forma oval o circular, que generalmente llevan impresa en relieve la imagen del cordero místico.

\section{ORIGEN Y ELABORACIÓN DEL AGNUSDEI}

Como ocurre en el caso de todas las materias utilizadas durante la misa o durante otras prácticas litúrgicas (pan, vino, agua, sal y aceite), los preceptos disponen la naturaleza de la materia que debe utilizarse en la fabricación de velas y cirios pascuales: siempre deben ser de cera pura y limpia. Los cirios pascuales eran bendecidos en una ceremonia especial, ocupaban un lugar concreto en el altar y ardían durante el período de tiempo más importande del año litúrgico, entre la Pascua y la Ascensión. A la cera del cirio pascual se le atribuyeron muy pronto virtudes "Salutíferas", adquiriendo así la categoría de "cera sagrada"; sabemos que desde el siglo vi los fieles se llevaban a casa pequeños fragmentos del mismo.

Entre los siglos VIII y XII, los pedazos informes se transformaron en figuras modeladas del cordero pascual, y más tarde, en el fragmento de cera se imprimió, con una especie de sello, la figura del cordero. A finales del siglo XII, la plancha de cera recibió una estampación por ambas caras mediante un molde especial provisto de tenazas (a modo de nieblero), que repite la técnica utilizada en la fabricación de hostias. Fue entonces, entre 1192 y 1198, cuando el cordero pascual estampado dio el nombre de Agnusdei a estas tablillas, cuya forma externa se ha mantenido en lo esencial durante ocho siglos.

Su elaboración presentaba siempre un carácter oficial y ritualizado, que convertía al Agnusdei en un objeto sacralizado mediante el contacto, por inmersión o por rozamiento, con elementos ligados de algún modo a la vida litúrgica como los restos de cera pascual o los santos óleos ${ }^{5}$. En un primer momento, la cera pascual fue mezclada directamente con el aceite consagrado antes de la fabricación de la tablilla. A partir de 1488 se

5 Benedetta MONTEVECCHI y Sandra VASCO ROCCA, Suppellettile ecclesiastica I (Firenze: Centro Di, Ministero per i Beni Culturali e Ambientali, 1988), p. 408. 
modificó este procedimiento, ya que se dispuso que la cera del Agnusdei debía ser pura, blanca y virgen. No obstante, se mantuvo la participación del aceite, ahora añadido al agua bendita que consagraba, mediante inmersión, estos objetos una vez elaborados en la ceremonia denominada bautismo de los Agnus.

Completaba el proceso la bendición papal, ritual que desde el siglo $\mathrm{XV}$ tenía lugar durante el primer año de pontificado del papa, el Miércoles, el Jueves y el Viernes Santo, y luego, cada siete años, el Viernes Santo. Esta periodicidad fue respetada en líneas generales, pero también se elaboraron Agnusdei en otros momentos puntuales, como en el caso de los años jubilares. Aunque con anterioridad el ritual tenía lugar en el propio Vaticano, a partir de 1608 van a ser los cistercienses de la iglesia de la Santa Cruz de Jesusalén de Roma los que detenten el derecho exclusivo de su preparación. Un interesante documento gráfico fechado en 1935 muestra el momento en el que la curia procede a la inmersión de los Agnus en la mencionada iglesia ${ }^{6}$. Los Agnusdei así sacralizados eran distribuidos en ocasiones litúrgicas entre cardenales, obispos, prelados y algunos fieles en las misas de los días sucesivos.

En general, y al margen de cuestiones puntuales, las noticias e informaciones de primera mano acerca del desarrollo de este complejo y simbólico ritual son poco conocidas. Por esta razón resulta de especial interés el contenido de la obra, fechada en 1607, Opvscvlos del origen, antiguedad, bendicion, significacion, virtud y milagros del Agnus Dei.... Compuestos, o (por mejor dezir) Recopilados de diuersos Autores, por el Padre Fray Andres de Soto... ${ }^{7}$, que realiza un detallado recorrido por todos y cada uno de los aspectos que conforman el carácter del Agnusdei. El texto está en buena parte mutilado, pero lo conservado muestra la preocupación del autor por reunir la mayor cantidad posible de datos acerca del proceso. De particular interés resultan los comentarios relativos al sacramento del Bautismo, antecedente del mencionado bautismo de los Agnus.

Los párrafos siguientes son un ejemplo de minuciosidad descriptiva, de manera que constituyen un interesante complemento del esbozo histórico presentado más arriba.

[...] Y porq depede la noticia de las ceremonias de la bendición del Agnus Dei, y las causas de su institución de saber los ritos y cermonias antiguas del bautismo,

6 Benedetta Montevecchi y Sandra VAsco Rocca, op. cit., p. 408.

7 Opusculos del origen, antiguedad, bendicion, significacion, virtud y milagros del Agnus Dei. Y del Agua bendita. Compuestos, o (por mejor dezir) Recopilados de diuersos Autores, por el Padre Fray Andres de Soto Fraile Menor, En Brusselas, En casa de Rutgerior Velpio, año de 1607. 
sera necessario tomar de aqui el fundamento por que fueron varios y diuersos en diuersos tiempos.

[...] Y el Sabbado Santo se bendezia la nueua fuente como agora y la pila del bautismo, y entrando los cathecumenos en la Iglesia mientras que se cantaba la Missa...

[...] Yendose despues poco a poco perdiendo esta costumbre de bautizar, y auiendo otra en la Iglesia, ordenaron los Romanos Pontifices que no pereciesse su memoria, y instituyeron la bendicion de los Agnus Dei, en la cual se haze casi todo aquello que se vsaua co los cathecumenos entonces. Lo qual se vera, si declaramos y referimos aqui las ceremonias que en ella se vsan.

En vn tiempo aparejaua la cera blanca y pura, de que se forman los Agnus: el maestro de la cera o cerero Mayor del sacro Palacio, y quellos que para si querian Agnus, y ponian la sobre el Altar de S.Pedro, y de allí lo lleuaua vno de los Subdiaconos del Papa a su Palacio, adonde en lugar para ello conuiniente el y otro Subdiacono y acolyto amasaban y sellauan los Agnus con gran deuocion y reuerencia, y ablandauan la cera co el Olio Sato y Chrisma que auia sobrado del año pasado; y esto se hazia el Sabado Vigilia de la Pascua, y despues presentauan los al Papa el dia que los auia de bendezir. Mas ya en estos tiempos el Sacristan del Papa con sus Capellanes y Clerigos de la Capilla, forman y amasan los Agnus parte de la cera del cirio Pascua del otro año, y parte de la cera nueua en la cantidad que juzgan ser menester, y ya no se ablanda con el Olio Santo, sino que puros y limpios se lleuan en vnas caxas al Palacio, y se presentan a su Santidad el dia que los ha de bendezir, que es el Iueues despues de la Dominica de la Resurreccion, en el qual despues de hauer oydo su Santidad Missa (laqual dize un Obispo en la Capilla adonde suele oyrla cada dia) se reuiste con el Amito, Alba, Cordo, Estola y Mitra, estando quatro Cardenales presentes, y otros prelados vestidos con sus capas Pontificales, y lo primero bendize el agua (que esta en un vaso de plata aouado) con la bendicion ordinaria, con q se bendize los Domingos, y despues dize otra oracion y hecha balsamo en ella y del olio de la Chrisma, diziendo palabras apropiadas a bendicion y consagracio, y despues de bendita y consagrada el agua, dize algunas oraciones sobre los Agnus, y essto hecho, cinese vn lienço muy limpio, y teniendo la mitra en la cabeça, se sienta junto a aquel vaso del agua y trahenle los Camareros los Agnus en vnos baçines de plata, y el co vna cuchara de plata agujereada, los hecha en el agua bendita, y los bautiza, y despues los quatro Cardenales q alli estan, los saca de eñña co otras cuchares de plata de la misma hechura, y los ponen en vnos vasos dorados o cochas [...]

[...] y luego comiençan a venir los Cardenales por su orden, vno a vno vestidos, con sus mitras en las manos, y auiendo primero hecho la debida reuerencia al Altar, se llegan ante su Santidad, y boluiendo las Mitras lo de arriba abaxo, reçiben dentro los Agnus que les da, los quales asi reçibidos le besan la mano, y asi hazen los Arçobispos y Obispos, y le besan sobre la rodilla, y los Protonotarios, Cubicularios, Capellanes, Familia, y los demas que alli se hallan toman los Agnus Dei en la mano, y besan el pie a su Santidad [...]

\section{El Capítulo I del libro concluye con la siguiente reflexión:}

De manera q estos Agnus son memoria de aquel bautismo y ceremonias, y se conserua con ellos y con su bendicion, y el ser de cera blanca y redodos, es porq 
entonces a los q se bautizauan, les dauan vn sello o bola de cera blaca, sellada con la Image del cordero, q trahyan colgada al pecho, [...] y llamauase insignia de persona triumfante y libre, y asi como por la vestidura blanca se denotaua que los bautizados, de esclauos del demonio, eran hechos libres y hijos de Dios, assi por aquella vola y globo se denotaua su libertad, y que eran ya ciudadanos del Paraiso, y triumfadores del demonio, y era sellada con la Imagen del cordero por su mansedumbre, porque conociessen que asi auian de ser mansos y pacificos.

En la iconografía cristiana Jesucristo aparece representado, entre otros, bajo el símbolo de un cordero, que sostiene la cruz o el estandarte de la Resurrección; su sangre, que mana del pecho, se recoge en un cáliz.

Las primeras fuentes escritas alusivas a esta representación se encuentran en el Antiguo Testamento, en un texto del profeta Isaías $(53,7)$, donde se recoge la temprana identificación de la muerte de Jesucristo en la cruz con el sacrificio del cordero pascual instituido por Moisés: "Era maltratado y se doblegaba, / y no abría su boca; / como cordero llevado al matadero, / como ante sus esquiladores una oveja muda / y sin abrir la boca".

La comparación de Jesucristo con el cordero aparece de nuevo en el Evangelio de San Juan y en el Apocalipsis. Juan el Bautista, el Precursor, exclama al ver a Jesús en la orilla del Jordán: "He aquí el Cordero de Dios, que quita el pecado del mundo" (Juan I, 29), y en una de las visiones del Apocalipsis $(5,9)$, Cristo se aparece a Juan bajo la forma de un cordero que abre el Libro cerrado y los siete sellos: "Tu eres digno de tomar el libro y de abrir sus sellos, porque has sido degollado y has rescatado para Dios con tu sangre hombres de toda tribu, lengua, pueblo y nación. Tu has hecho para Dios un reino de Sacerdotes reinando sobre la tierra".

Desde entonces, la imagen simbólica que queda configurada en base a estos textos se repetirá con extraordinaria frecuencia en todo el Occidente cristiano, en oposición a lo que ocurrió en el área de influencia de la Iglesia de Oriente, donde fue prohibida en $629^{8}$.

Siguiendo estas pautas iconográficas, el Agnusdei presenta en el anverso un cordero de Dios de hechura estereotipada: es el cordero pascual, con nimbo y estandarte, que aparece sentado sobre el libro con los siete sellos. Además, incluye una leyenda en latín que casi siempre dice: "Ecce Agnus Dei, qui tollit pecata mundi" $=$ "Cordero de Dios, que quita el pecado del mundo". En el caso de algún ejemplar fechado en el siglo XV se advierten ciertas variaciones, apareciendo el cordero de pie, rodeado de una leyenda que dice "Agne Dei, miserere mei, qui crimina tollit" ${ }^{\text {. }}$ Bajo el

8 Louis REAU, Iconographie de l'Art Chrètien (Paris: Presses Universitaires de France, 1983), Vol. II, p. 30. 
cordero, la tablilla de cera presenta a menudo el escudo papal, un nombre de Papa y una fecha.

En el reverso puede estar estampada la imagen del Crucificado, de la Virgen María o de un santo, una referencia a las particulares devociones hagiográficas del Papa, apareciendo también el nombre del pontífice y una fecha, así como una inscripción alusiva a la imagen. Además, como ocurre en muchas medallas bendecidas, algunos Agnusdei llevan la especificación de la procedencia, es decir, Roma, que se dispone indistintamente en ambas caras.

En cuanto a su forma, los ejemplares más antiguos pueden ser circulares, pero lo más común es que sean ovales, oscilando su tamaño entre 1 y 20 cms. (figs. 1-2).

Según la teoría más comúnmente aceptada, la forma adoptada por las tablillas de Agnusdei es una imitación de las bullae romanas - discos de oro o de otras materias que llevaban colgados del cuello los jóvenes romanos. Ciertos datos parecen indicar que la promoción del Agnus fue un

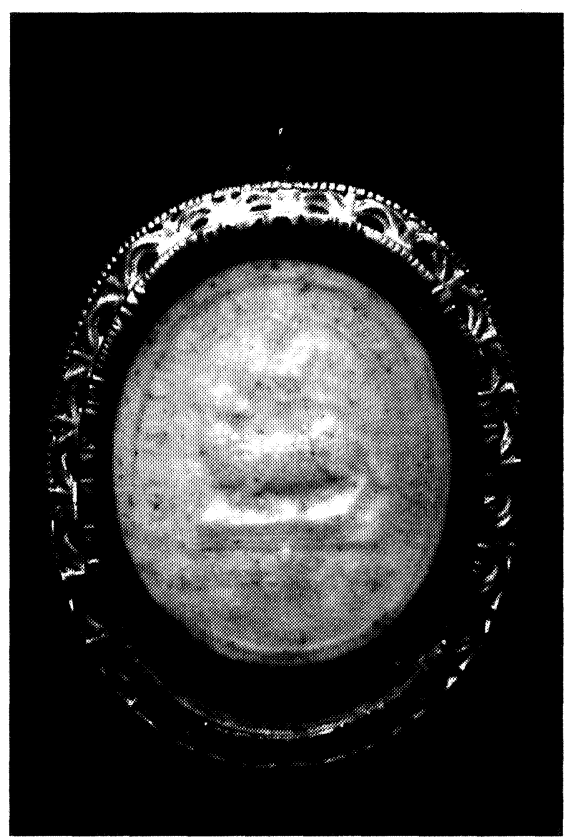

Fig. 1.-Anverso del Agnusdei de Pío VI. N. ${ }^{\circ}$ inv. 8949.

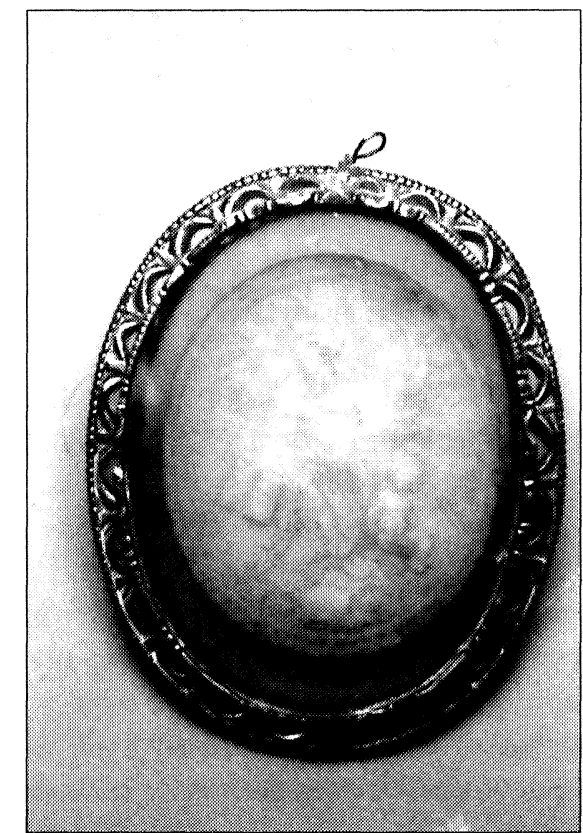

FIG. 2.--Reverso del Agnusdei de Pío VI N. ${ }^{\circ}$ inv. 8949.

9 Geformtes Wachs, Austellung 1980/1981 (Basel: Schweizerisches Museum für Volkskunde, 1980), pp. 60 y 61, n. 87 y 88 . 
intento, por parte de la Iglesia, de oponerse a la persistente creeencia pagana en el poder amulético de las bullae. Por otra parte, el círculo de cera recuerda a la hostia consagrada colocada bajo vidrio en la custodia; a veces, estas hostias llevan impresa la imagen del Agnus Dei ${ }^{10}$.

\section{LAS VIRTUDES DEL AGNUSDEI}

Desde la Edad Media la creencia popular ha atribuido al Agnusdei enormes poderes contra todo tipo de males, de ahí que su posesión fuera muy codiciada. Conocemos algún Agnus en el que se hace mención expresa de esas cualidades, como ocurre en el ejemplar más antiguo de la colección del Schweizerisches Museum für Volkskunde de Basel, fechado en el siglo $\mathrm{XV}$, que conserva sobre el propio medallón una filacteria de papel con la siguiente leyenda: "Agnus Dei de cera et balsamo consecratus a papa contra daemones et tempestates" ${ }^{11}$. La fórmula que tan escuetamente aparece en esta inscripción resume el amplio campo de influencia sobre el que ejerce su poder el Agnus. La Iglesia Romana, sabedora del fuerte arraigo de esta creencia, no sólamente no la combatió, sino que contribuyó conscientemente a extenderla, canalizándola a través de textos impresos.

En 1752 Benedicto XIV (1740-1758) estableció la obligatoriedad de entregar, junto al Agnusdei, un impreso con explicaciones acerca de su efecto y aplicación. No obstante, lo que a mediados del siglo xviII se había convertido en norma era ya un hecho corriente al menos ciento cincuenta años antes.

En el ámbito español, uno de los primeros ejemplos conocidos que atestiguan el interés de la Iglesia en subrayar los valores del Agnusdei es el mencionado Opusculos... del Agnus Dei, editado en Bruselas en 1607, que dedica un buen número de páginas a exponer sus virtudes y milagros. También a comienzos del siglo XVII corresponde la hoja anómina titulada Las virtudes del Agnus Dei, con texto impreso por una sola cara y enmarcado por orla tipográfica. En este caso no existe ningún dato que indique que era entregada en Roma junto al Agnus, pudiendo tratarse más bien de un impreso divulgativo destinado a ser expuesto en lugares de culto (fig. 3). El texto dice lo siguiente:

Las virtvdes, y propiedades del Agnus Dei, son muchas, sacadas de las oraciones muy deuotas, que el Papa dize cuando los consagra. Y estas aprouechan à los

10 Martha J. Egan, Relicarios. Devotional miniatures of the Americas (Santa Fe: Museum of New Mexico Press, 1993), p. 66.

11 Geformtes Wachs, pp. 60-61. 


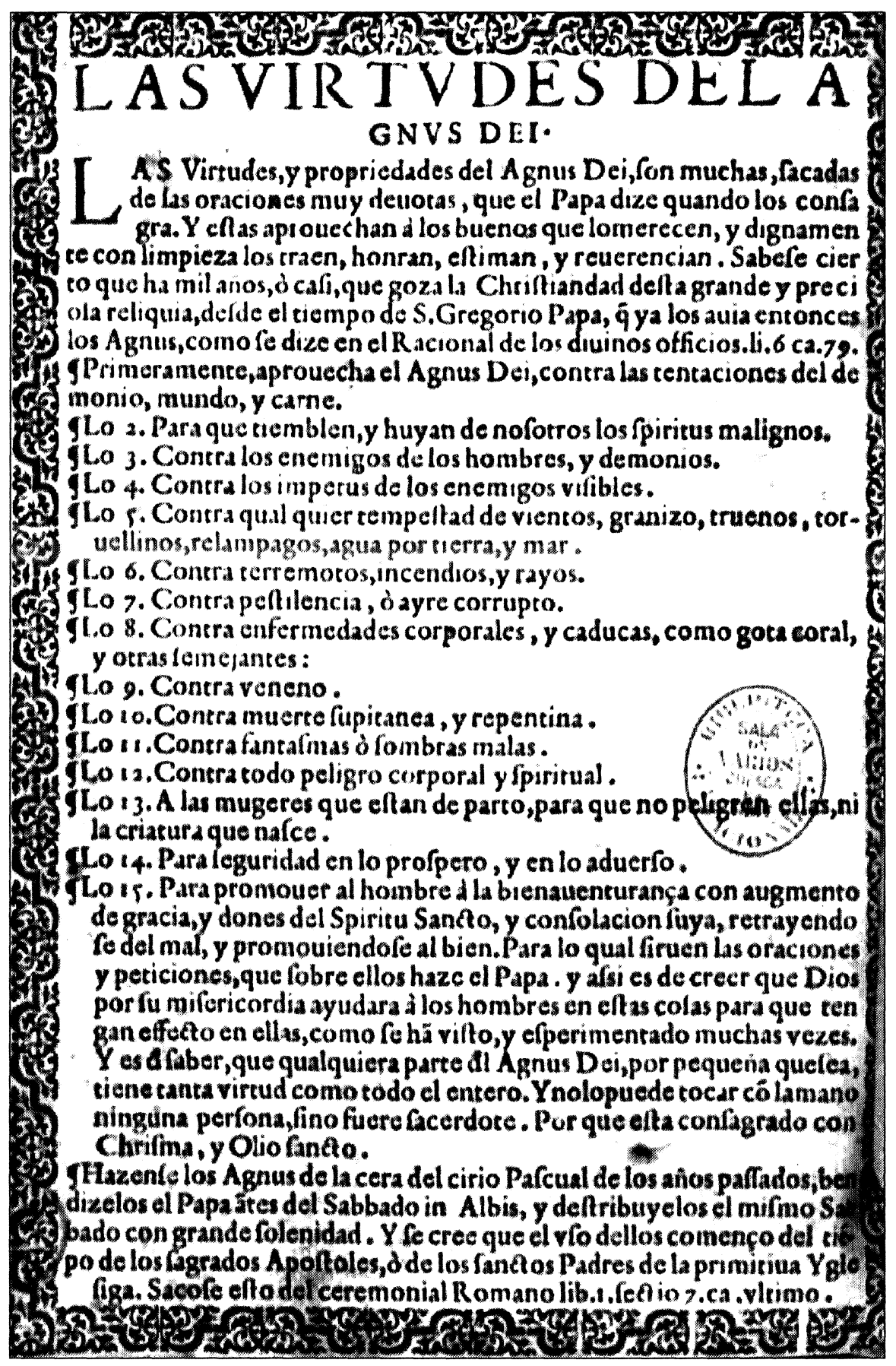

FIG. 3.-Las virtudes del Agnus Dei. Biblioteca Nacional. Madrid. 
buenos que lo merecen, y dignamente con limpieza los traen, honran, estiman y reuerencian. Sabese cierto que ha mil años, ò casi, que goza la Christiandad desta grande y preciosa reliquia, desde el tiempo de San Gregorio, q ya los había entonces los Agnus, como se dize en el Racional de los diuinos officios li. 6. ca. 79. Primeramente, aprouecha el Agnus Dei contra las tentaciones del demonio, mundo y carne.

Lo 2. Para que tiemblen y huyan de nosotros los spiritus malignos.

Lo 3. Contra los enemigos de los hombres y demonios.

Lo 4. Contra los impetus de los enemigos visibles.

Lo 5. Contra qual quier tempestad de vientos, granizo, truenos, toruellinos, relampagos, agua, por tierra, y mar.

Lo 6. Contra terremotos, incendios y rayos.

Lo 7. Contra pestilencia, ò ayre corrupto.

Lo 8. Contra enfermedades corporales, y caducas, como gota coral, y otras semejantes.

Lo 10. Contra muerte supitanea, y repentina.

Lo 11. Contra fantasmas ò sombras malas.

Lo 12. Contra todo peligro corporal y spiritual.

Lo 13. A las mugeres que estan de parto, para que no peligren ellas ni la criatura que nasce.

Lo 14. Para seguridad en lo prospero, y en lo aduerso.

Lo 15. Para promouer al hombre a la bienauenturança con augmento de gracia, y dones del Spiritu Santo, y consolación suya, retrayendose del mal, y promouiendole al bien. Para lo cual sirven las oraciones y peticiones, que sobre ellos haze el Papa. Y asi es de creer que Dios por su misericordia ayudara à los hombres en las cosas para que tengan effecto en ellas, como se ha visto, y experimentado muchas vezes. Y es d saber, que cualquier parte dl Agnus Dei, por pequeña que sea, tiene tanta virtud como todo el entero. Y no lo puede tocar co la mano ninguna persona, sino fuere sacerdote. Porque está consagrado con Chrisma y Olio sancto.

Hazense los Agnus de la cera del cirio Pascual de los años passados, bendizelos el Papa âtes del Sabbado in Albis, y destribuyelos el mismo Sabbado con grande solenidad. Y se cree que el vso dellos començo del tiempo de los sagrados Apostoles, ò de los sanctos Padres de la primitiva Yglesia. Sacose esto del ceremonial Romano, lib. I. sectio 7. Ca. vltimo.

Entre 1723 y 1738 vieron la luz los siete volúmenes de un ambicioso proyecto titulado Cérémonies et coutumes religieuses de tous les peuples du monde, valioso por diversos motivos, entre los que destaca su excepcional aparato iconográfico, obra del dibujante y grabador Bernard Picart. En el capítulo correspondiente a las ceremonias católicas, Picart dibuja una plancha en la que figuran una serie de objetos asociados a la práctica del catolicismo: un escapulario, un rosario de quince decenas, un rosario ordinario, una sortija que los caballeros de la Orden de Malta utilizan para rezar el rosario, una decena también para rezar el rosario, un pan de Sta. Genoveva, una medalla bendita de cobre y una copia exacta de la boja 
impresa que el papa entrega con los Agnusdei. Además del texto en francés, en la hoja figuran un Agnusdei redondo y el escudo de armas del Papa Alejandro VII, cuyo pontificado tuvo lugar entre 1655 y $1669^{12}$. En el encabezamiento de la hoja se lee:

Las virtudes del Agnus Dei, compuesto de aceite consagrado, bálsamo y cera pura. Extracto del libro llamado el Ceremonial, donde hablando de la bendición de estos, las palabras siguientes, se encuentran registradas para este fin de esta manera.

En la parte central el texto dice:

Se lee que el papa Urbano V envió al Emperador de los Griegos tres Agnus Dei con estos versos y palabras.

Los truenos ahuyenta

Los pecados borra

Preserva del incendio

Y de la inundación

Preserva de la muerte repentina

Ahuyenta los diablos

Amansa a los enemigos

El hijo y la madre

Son alejados de todo peligro

Quien trabaja para hacerlo

Da mucho poder

A los dignos de tenerlo

La parte, aunque pequeña,

Es tan provechosa como la grande.

A continuación figura "La oración que el Papa pronuncia en la Bendición del Agnus Dein.

Que borre los pecados, que imparta perdón, que confiera gracias.

Que tocándole y viéndole los cristianos se vean impulsados a alabar a Dios.

Que la ventisca, heladas, nevadas y tempestades, la furia de los vientos y de las tormentas sean disminuídas y detenidas.

Que ante el saludable y glorioso estandarte de la cruz que en él figura los espíritus malignos se espanten y huyan.

Que aquel que le lleve consigo, tenga virtud contra las ilusiones, engaños, astucias y fraudes del diablo y de los espíritus malignos.

Que ninguna tempestad, adversidad, aire pestilente o corrompido, ni mal caduco; ninguna tormenta, tempestad, ningún fuego y ninguno otro revés de tiempo puedan lastimar, hacer daño o prejudicar a quien le lleve consigo.

Que durante el parto sean protegidos la madre y el niño.

Que todos los que le lleven consigo tengan siempre la seguridad de no temer ningún peligro, que no teman a las sombras, que ninguna crueldad del Diablo les perjudique, que no puedan ser engañados, que se vean exentos de todos los peligros, del fuego, del rayo, de la tormenta y de las tempestades; Y que las mujeres den a luz sin trabajo y sean libradas de todo mal y de todo peligro.

12 Cérémonies et coutumes religieuses de tous les peuples du monde. Dessinèes par Bernard Picart (Paris: Éditions Herscher, 1988), p. 247. 
En la parte inferior figuran la fecha y el lugar de impresión: "Roma, Imprenta de la Cámara Apostólica. 1662. con permiso de los superiores".

En el Schweizerisches Museum für Volkskunde de Basel se conservan dos hojas impresas cuyos textos presentan ligeras variaciones con respecto a éste, manteniendo el contenido en lo esencial. Uno de ellos, fechado en Roma en 1877, con texto en latín y título De ritu et usu cerarum formarum quea benedici et consecrati a romano pontifice y otro, impreso en la Tipografia Poliglotta Vaticana en 1935, con texto en alemán y título Weibe und gebrauch der Agnus $D e i^{13}$. En relación a éste último, hay que suponer que en la década de los años treinta el Vaticano proporcionaba los textos no sólo en alemán sino también en español, francés o italiano, como es usual en el caso de estampas, libros y todo tipo de escritos. Es evidente, pues, que la Iglesia ha demostrado un interés especial por mantener vigente durante más de cuatro siglos la norma de entregar un texto impreso acompañando al Agnusdei propiamente dicho.

Como conclusión puede decirse que, en relación directa con la liturgia romana, el Agnusdei se considera un sacramental, que permite la realización de un rito sagrado instituido por la Iglesia para obtener beneficios, básica aunque no exclusivamente de orden espiritual. Siguiendo las recomendaciones escritas que partían del mismo Vaticano, los Agnusdei fueron llevados por las mujeres devotas de la Europa católica, siendo especialmente populares en España, Portugal y sus colonias. Así, cuando Marie Cathaline la Jumel de Berneville, Condesa D'Aulnoy, visitó España entre los años 1679 y 1681, se hizo eco de la costumbre que tenían las españolas de incluir entre sus joyas los Agnus $D e i^{14}$. También Martha Egan recoge numerosos ejemplos de la presencia del Agnusdei en todo el área americana que estuvo bajo influencia española. Incluso en un lugar tan apartado como San Antonio, Texas, las mujeres atesoraban estos objetos sagrados: en el inventario de bienes de Maria Josefa Granados, fechado en 1787, se incluyen tres Agnus de cera ${ }^{15}$.

\section{AGNUSDEI VERSUS RELICARIO}

Con todos estos antecedentes resulta contradictorio comprobar cómo los Agnusdei, cuya elaboración, virtudes y utilización han sido reglamen-

13 Geformtes Wachs, p. 66, n. ${ }^{\circ} 101$ y p. 68, n. ${ }^{\circ} 103$ respectivamente.

14 Marie Catherine D'AulNoY, Relación del viaje de España (1679-1681) (Madrid: Akal, 1986), p. 170.

15 Martha J. EGAN, op. cit., p. 69. 
tados por la Iglesia hasta en los más mínimos detalles, aparecen raramente mencionados en catálogos y publicaciones dedicadas total o parcialmente a objetos devocionales.

En este sentido hay que llamar la atención sobre un hecho que puede parecer obvio pero que, sin embargo, no está exento de interés. Se trata del nombre, es decir, de la palabra con que se han designado y se designan los objetos estudiados. Porque la expresión latina Agnus Dei - Cordero de Dios- encierra una diversidad de significados compleja y sorprendente, consecuencia del enfoque adoptado por cada una de las fuentes y repertorios consultados: así, es posible encontrar definiciones en las que predomina el carácter religioso, el sentido artístico, la visión simbólica, etc.

Esta riqueza conceptual — que se materializa, como se verá más adelante, en un interesante desarrollo formal- constituye, a mi juicio, una prueba inequívoca de la continuada vigencia del Agnusdei en el ámbito de la cultura occidental desde la Edad Media hasta bien entrado el siglo XX.

En la colección del Museo Nacional de Antropología se conservan veinticinco medallones o tablillas de cera en los que aparece impresa la imagen del Cordero. En su mayoría son de forma ovalada, aunque hay algunos circulares, y su tamaño es variable, oscilando entre los $3 \mathrm{~cm}$. del ejemplar más pequeño y los $15.5 \mathrm{~cm}$. del mayor. Por lo general han llegado hasta nuestros días guardados en el interior de unos estuches fácilmente transportables y de carácter más o menos artístico, aunque también hay que señalar la existencia de un conjunto de Agnusdei colocados en marcos, con la evidente intención de ser dispuestos en la pared.

Además, la mayor parte de estos medallones de cera tienen en común el haber sido adquiridos por el antiguo Museo del Pueblo Español entre 1941 y 1955, careciendo casi sin excepción de referencias geográficas, esto es, de lugar de procedencia. Por otra parte, todos aquéllos que ingresaron en el Museo con anterioridad a 1952 están incluidos en el conocido Catálogo de la colección de Relicarios, de la serie Trabajos y Materiales del Museo del Pueblo Español, que publicó Juan Contreras y López de Ayala, Marqués de Lozoya, en torno a dicho año. A pesar de que las características físicas de los medallones de cera se ajustan completamente a la definición de Agnusdei expuesta más arriba, el hecho de aparecer en el citado Catálogo ha adjudicado a estos objetos de forma automática el nombre con el que desde entonces son conocidos en el ámbito del Museo: ese nombre es relicario.

Con la intención de justificar y razonar de alguna manera la agrupación de objetos tan diferentes entre sí que se describen en las páginas siguientes, unificados bajo el término relicario, el Marqués de Lozoya afirma: 
Los relicarios que se guardan en el Museo del Pueblo Español no tienen la calidad artística ni el valor histórico de las piezas que hemos reseñado a guisa de antecedentes. En ellos el concepto de 'relicario' es más amplio, pues lo aplicamos, no solamente a los objetos destinados a contener reliquias propiamente dichas, sino a toda joya de adorno personal en la cual el ornato se concierta en torno de un objeto de carácter religioso, frecuentemente una pintura o una estampa, un pequeño esmalte, una diminuta figurilla labrada en metal o en marfil ${ }^{16}$.

Más adelante, al señalar las características del grupo de relicarios denominado "Colgantes conteniendo imágenes", el autor escribe: "La fantasía de estos imagineros populares es inagotable y utiliza toda suerte de recursos: relieves de cera, estatuillas de hueso, plaquitas grabadas o esmaltadas, figurillas vestidas con sedas de colores, medallas troqueladas o cinceladas, pequeños bordados, etc.. ${ }^{17}$. Este párrafo, en el que por primera vez aparecen mencionados los relieves de cera, muestra al mismo tiempo un error de bulto, ya que el Marqués pone su fabricación en manos de unos supuestos imagineros populares que, como hemos visto, nunca existieron en el caso de los Agnus.

Esta declaración de intenciones - en la que la palabra Agnusdei ni se menciona - tampoco lleva implícita una uniformidad de criterio a la hora de asignar nombre a los relieves de cera que aparecen a lo largo de las descripciones del Catálogo, de manera que es posible encontrar términos tan distintos como sello de cera ${ }^{18}$, relieve en cera ${ }^{19}$, reliquia ${ }^{20}$, lámina de cera $^{21}$, cuando no simplemente cera ${ }^{22}$ para designar un mismo objeto. En algún caso se advierte, además, la total confusión del autor al identificar la materia prima que conforma el medallón en cuestión, refiriéndose a él como lámina de alabastro ${ }^{23}$.

Sin embargo, el Marqués de Lozoya no sólo reconocía y valoraba estos objetos sino que también los echaba en falta en las colecciones del Museo, como se desprende del comentario expresado en el Catálogo de

16 Juan Contreras y LóPez DE Ayala, Marqués de Lozoya, Catálogo de la colección de relicarios. Trabajos y materiales del Museo del Pueblo Español (Madrid, ca. 1952), pp. 4-5.

17 Juan Contreras y López de Ayala, op. cit., p. 7.

18 N. ${ }^{\circ}$ inv. 8949 y 9739.

19 N. ${ }^{\circ}$ inv. 9550.

20 N. ${ }^{\circ}$ inv. 8882 y 9653.

21 N. ${ }^{\circ}$ inv. 9684, 11084, 11086, 11088 y 11606.

22 N. ${ }^{\circ}$ inv. 11846 y 12538.

23 N. ${ }^{\circ}$ inv. 11110. 
la colección de Medallas, donde afirma lo siguiente: “En cambio, no he podido hallar en la colección ejemplares de otro colgante del cual hay numerosas referencias literarias: el Agnus Dei, del cual tengo apuntadas curiosas citas referentes a los siglos XVI y XVII ${ }^{24}$.

A pesar de este desconcertante descuido, el trabajo que realizó el Marqués partiendo de la colección de relicarios del Museo del Pueblo Español -que debe considerarse, con sus evidentes limitaciones, pionero en su género, producto de su época y reflejo de una compleja tradición cultural- no constituye el único antecedente en el que se vislumbra la confusión que parece existir en torno a los Agnus.

Ya a finales del siglo XVI y comienzos del XVII, se advierte con claridad una identificación absoluta entre reliquia y Agnusdei. En el camarín de los despojos de la batalla de la Liga, descrito en el inventario de bienes de don Hernando Carrillo y Mendoza, conde de Priego, fechado en 1579, se disponían los tesoros más preciados de su dueño, que participó en la batalla de Lepanto (1571). Distribuidas por los estantes y mesas del camarín había distintas reliquias suyas, entre las que aparece una amplísima serie de objetos pertenecientes a Pío V: su túnica, un bonete rojo y otro de raso blanco, sus zapatos de terciopelo carmesí, un libro de horas en que rezaba el rosario y un agnus dei grande con sus armas ${ }^{25}$.

Otra referencia interesante en esta misma línea, que puede arrojar un poco de luz sobre el criterio adoptado en su momento por Juan Contreras, aparece recogida en el Tesoro de la Lengua Castellana o Española de Sebastián de Covarrubias, publicado en 1611. La expresión latina Agnus Dei aparece ya sustantivada - Agnusdei-, y con doble acepción:

Agnusdei. Es el Christo Redentor nuestro, a quien llamamos cordero, no en propiedad, sino en similitud, como en muchos lugares se llama vid, piedra, puerta, pastor, león; pero en razón de la mansedumbre, de la limpieza y castidad e inocencia y obediencia, y en quanto fué sacrificado al Padre celestial por los pecados del género humano, con gran propiedad se llama cordero. Y la Yglesia instruyda por el Espíritu Santo, en el sacrificio de la Missa, antes de la Comunión,

24 Juan Contreras y López De Ayala, Marqués de Lozoya, Catálogo de la colección de medallas. Trabajos y materiales del Museo del Pueblo Español (Madrid, ca. 1952), p. 5.

25 J. Miguel Morán y Fernando CheCa Cremades, El coleccionismo en España. De la cámara de maravillas a la galería de pinturas (Madrid: Ediciones Cátedra, S.A., 1985), p. 164. Por su parte, en P. MULler, Jewels in Spain, 1500-1800 (New York: The Hispanic Society of America, 1972), p. 73, n. ${ }^{\circ} 105$, puede verse el reverso de un Agnusdei de Pío V, en cuyo centro se representa la Adoración de los Reyes Magos. Las armas a las que alude el citado inventario son en realidad el escudo papal, cuyo pontificado tuvo lugar entre 1566 y 1572. 
instituyó se dixesse y se cantasse la precación: Agnus Dei qui tollis peccata mundi, etc. Y el Baptista le señaló con este nombre: Ecce Agnus Dei. Agnus Dei, reliquia santa, que bendize el sumo Pontífice y consagra el primer año de su pontificado; y los demás que regularmente dizem ser de siete en siete años. Está a cargo del sacristán y de los capellanes disponer la cera; en la cual entra la de los cirios pascuales del año de antes, y con gran curiosidad, limpieza y reverencia y en diferentes moldes sacan los agnus de diferentes tamaños y diversas figuras, en la una parte, y en la otra todos tienen el cordero, que da nombre a esta reliquia. Y presentados a su Santidad los bendize en la capilla y consagra con grandes ceremonias, echándolos en las vazías del agua que ha bendezido, derramando sobre ellas el bálsamo y la crisma, dize muchas oraciones. La consagración de los Agnus Dei es muy antigua, y la devoción que con ellos se tiene. Léese que el papa Urbano quinto embió al emperador de Grecia un Agnus Dei, y con él ciertos versos muy devotos en que se declara la excelencia desta santa reliquia, pues vale para contra tempestad, el fuego, los rayos, peste y contra los incursos del demonio; y assí deve ser tratada con mucho respeto y reverencia ${ }^{27}$.

Parece indiscutible que Covarrubias, contemporáreo de Fray Andrés de Soto y probablemente conocedor de su obra, tuvo acceso a una completa información al respecto, porque además de recoger la simbología del Cordero, fundamental para comprender el significado del Agnus, ofrece datos precisos acerca del ritual que rodea su elaboración, haciendo referencia incluso a una parte del texto, citado más arriba, en el que se narra el envío de Agnusdei realizado por Urbano V al Emperador de los griegos. Pero, al mismo tiempo, define el Agnusdei como reliquia, una reliquia santa, de cera, que bendice el Papa.

Poco más de un siglo después, el Diccionario de Autoridades (17261737) ofrece una definición más escueta y precisa, aunque en ella el concepto de reliquia sigue de alguna manera presente:

Agnusdei: Unos pedazos de cera blanca, amasados por el Papa, con polvos de reliquias de santos, a quien sirven y asisten para esto algunos Cardenales y Prelados: métese esta cera entre dos formas, que la una tiene abierta a sincel la forma de un Cordero con la inscripción Agnusdei, y la otra la Imagen de Cristo, de nuestra Señora, ú de algún Santo, con su inscripción, y el nombre de Pontífice que los hace y bendice: y así salen estas formas en la cera de medio relieve, y regularmente de hechura circular, ó elyptica ${ }^{27}$.

Por otra parte, las fuentes mencionadas son fiel reflejo del espíritu de un momento histórico concreto. Hay que recordar que el culto a las reliquias fue confirmado en la sesión de clausura del Concilio de Trento

26 Sebastián DE COVARRuBias, Tesoro de la Lengua Castellana o Española (Madrid: Ed. Turner, 1984), pp. 49-50.

27 Diccionario de Autoridades (Madrid: Gredos, 1969), p. 117. 
(3-4 de diciembre de 1563), siendo condenados aquellos que lo rechazaron, de manera que el arte religioso en general se hizo eco a partir de entonces de esta posición doctrinal de la Iglesia. En este contexto cabe situar el culto a los santos, fomentado como respuesta a su rechazo por parte de los protestantes. En opinión de Morán y Checa, al mismo tiempo que la Iglesia estaba reivindicando el papel intercesor de los santos y de los mártires, insistía sobre la importancia de las reliquias y su valor devocional, defendiéndolas primero en Trento y posteriormente en el Concilio de Bourges. Conservadas en relicarios, altares o grandes camarines que, como el de las Descalzas Reales de Madrid, mantenían el espíritu y la organización de las Wunderkammern, se exponían a la contemplación de los fieles en las grandes solemnidades ${ }^{28}$.

Puesto que ésta era la doctrina oficial de la Iglesia Católica, Felipe II se adhirió a ella con entusiasmo, iniciándose así la estrecha relación entre reliquias y devoción que caracterizará la práctica religiosa en nuestro país durante las centurias siguientes. Por ello no es extraño pensar que todos y cada uno de los elementos guardados en el interior de los estuchesrelicario (medallas, bajorrelieves, esculturas de bulto redondo, etc.), tanto de los que forman parte de collares, brazaleras o dijeros, como de aquéllos destinados al espacio doméstico o de culto bajo la forma de cuadros, cruces, etc, sean considerados reliquias. El gran peso cultural adquirido por las reliquias en el ámbito del catolicismo hispano ha llevado incluso a algún autor a establecer una categoría específica de relicarios, caracterizada básicamente por la existencia de un Agnusdei, esto es, de una lámina de cera, en su interior ${ }^{29}$.

Estas referencias literarias e históricas resumen con claridad las circunstancias que favorecieron la identificación entre reliquia y Agnusdei. Si las sumamos a la necesidad de llevar consigo el medallón en cuestión - debía llevarse con limpieza y no lo puede tocar con la mano ninguna persona, sino fuere sacerdoten-, a la conveniencia de su uso constante para beneficiarse de sus virtudes y a la moda de la joyería de carácter religioso, todo ello se materializa - no sabemos si como causa o como efecto- en el aspecto puramente formal de las cajas o estuches que hoy se definen comúnmente como relicarios. Otra peculiaridad que ha contribuido en buena medida a establecer una equivalencia entre ambos términos es que, con frecuencia, las tablillas de cera que conforman el Agnusdei aparecen en el interior de los estuches junto a reliquias propiamente dichas (fragmentos de materia orgánica, de textiles o de minerales). Parece

28 J. Miguel Morán y Fernando Checa Cremades, op. cit., p. 232.

29 Martha J. EGAN, op. cit. 
claro, sin embargo, que el hecho de compartir un mismo espacio físico no equivale a pasar por alto las particulares características del Agnusdei.

El problema se plantea cuando estas láminas de cera han llegado hasta nuestros días exentas, es decir, fuera de un contenedor. Esta circunstancia que, por una parte, nos presenta el objeto en su estado verdaderamente original, coloca sin embargo al Agnus en una posición hasta cierto punto anónima que en nada ha favorecido su inclusión dentro de la categoría de objetos devocionales. Así, en alguna subasta se ha visto un Agnusdei sin estuche catalogado como "relieve sobre cera con el Agnus Dei en el reverson. Es decir, se detecta una cierta tendencia a valorar por encima de todo la calidad y las cualidades del contenedor en detrimento del contenido ${ }^{30}$.

\section{LOS AGNuSDei EN EL MUSEO}

Según lo expuesto hasta ahora, los Agnusdei son objetos que se caracterizan por ofrecer, entre otras peculiaridades de indiscutible interés para el estudio de la práctica religiosa, unas coordenadas de tiempo y de lugar precisas e inequívocas, que van unidas indisolublemente a su aspecto formal. Que este presupuesto teórico se confirme en realidad depende en primer lugar del estado de conservación que presente cada pieza, porque no hay que olvidar que la cera es una materia extremadamente frágil, muy sensible además al impacto de la luz, que oscurece el color blanco que le es propio, transformándolo en un color anaranjado.

La calidad inicial del relieve del medallón, el uso continuado del mismo, así como el hecho de haber estado guardado o no en el interior de un estuche, son otras circunstancias que van a influir en el volumen de información obtenido en cada caso. Por otra parte, al compartir el espacio de los estuches con reliquias, estampas, pinturas bajo vidrio, etc., es bastante habitual que el Agnusdei sólo sea visible por una de sus caras. Finalmente, puede haber servido de soporte directo de una o varias reliquias: es frecuente, por ejemplo, que sobre el medallón de cera aparezcan unas astillas de madera formando una cruz latina, que constituyen la reliquia denominada Lignum Crucis, fragmento de la cruz en la que murió Jesucristo ${ }^{31}$.

30 En el Museo Nacional de Artes Decorativas de Madrid está expuesto un estuche de plata que guarda un Agnusdei de Inocencio $X$ en su interior ( . $^{\circ}$ inv. 1485). La pieza, sin embargo, muestra la cara que presenta la imagen de San Francisco pintada sobre cobre, quedando oculto el medallón de cera.

31 El Lignum Crucis aparece asociado a cinco Agnusdei del Museo Nacional de Antropología, n. ${ }^{\text {os }}$ inv. 8882, 11606, 11864, 12538 y 17678. 
La concurrencia en mayor o menor medida de cada uno de estos factores será la que dificulte, llegando incluso a impedir, la percepción de la iconografía y de las leyendas. Cuando no sea posible obtener información directa, serán otros elementos tales como, ahora sí, los estuches (técnica, aspecto formal) y su contenido (texto y tipo de escritura de las filacterias, elementos textiles, fragmentos de naipes y/o estampas dispuestos en el alma, etc.), los que permitan establecer la cronología aproximada de la pieza (fig. 4).

Así, en el caso del Museo Nacional de Antropología sólo en diecisiete de los veinticinco Agnusdei conservados puede leerse el nombre del pontífice que los consagró y/o la fecha de la consagración.

El ejemplar más antiguo de la colección, pegado sobre un soporte de cartón y seda y rodeado de reliquias dispuestas a modo de retablo, muestra sólo el reverso, en el que aparece el busto nimbado de Jesucristo (fig. 5). Corresponde al pontificado de Pío V (1566-1572) y presenta ciertas peculiaridades que le convierten en una pieza excepcional. En primer lugar, el busto de Jesucristo está pintado en azul y rojo. Con frecuencia y como expresión de devoción, los Agnusdei fueron policromados a lo largo del siglo XVI. Ya en 1572 el Papa Gregorio XIII (1572-1585), en un esfuerzo por mantener la simbólica pureza del color blanco de la cera, prohibió, bajo pena de excomunión, todo tipo de sobredorados o coloraciones̀. A

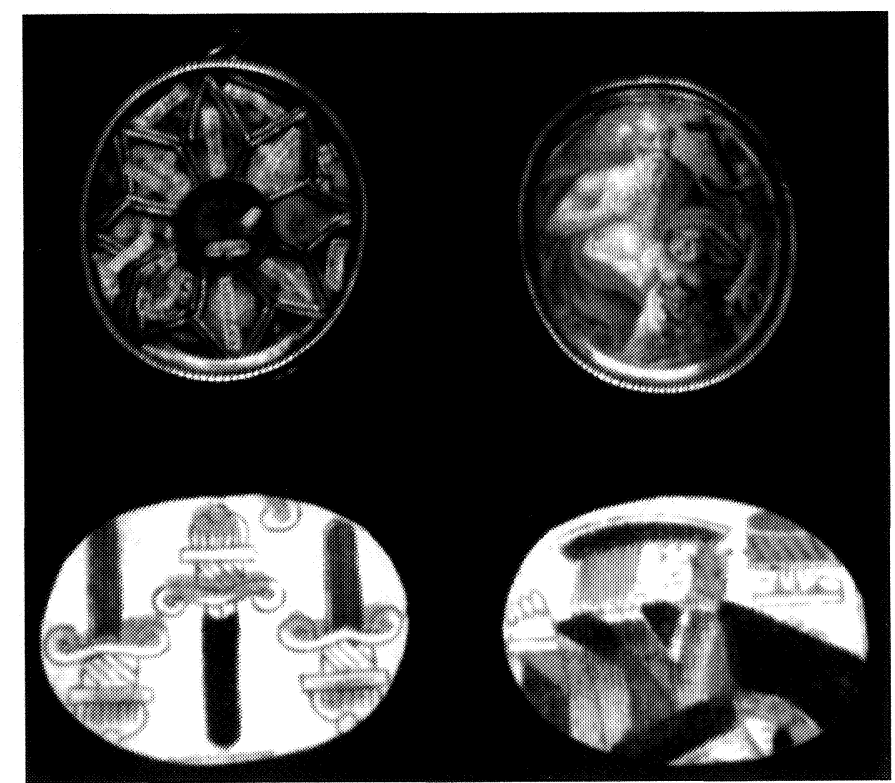

FIG. 4.-Estuche con Agnusdei central, rodeado de reliquias. En el interior, naipes recortados. N. ${ }^{\circ}$ inv. 17678. 


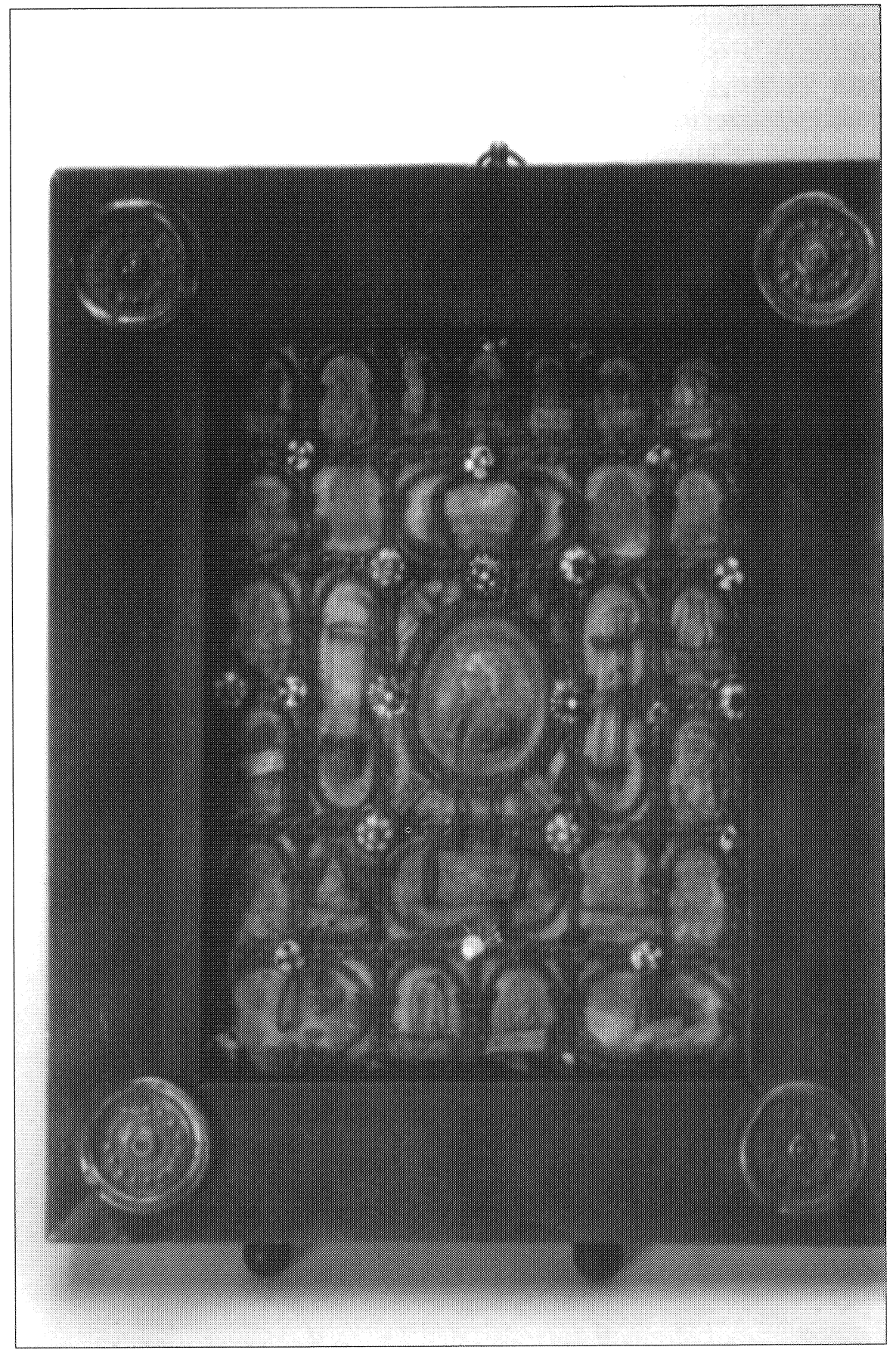

FIG. 5.-Agnusdei central policromado, de Pío V, rodeado de reliquias. N. ${ }^{\circ}$ inv. 8601. 
pesar de la existencia de algunos Agnusdei iluminados correspondientes a los años posteriores, claro testimonio de que la prohibición fue ignora$\mathrm{da}$ al menos por algunos fieles, este tipo de piezas pintadas son en realidad muy poco frecuentes ${ }^{32}$. Por otra parte, el conjunto tiene unas dimensiones reducidas y está enmarcado bajo vidrio, lo que parece indicar que estuvo ubicado en un espacio doméstico.

El resto de los medallones fechados se distribuyen a lo largo de un siglo, desde fines del siglo XVII a 1779. Al año jubilar 1690 corresponde un Agnus de Alejandro VII (1689-1691), sin duda el de mejor factura de la colección, de tal manera que el Marqués de Lozoya consideró que la pieza estaba realizada en alabastro (fig. 6). En 1714, año catorceavo de pontificado, se fecha un Agnus de Clemente XI (1700-1721) (fig. 7). Y al

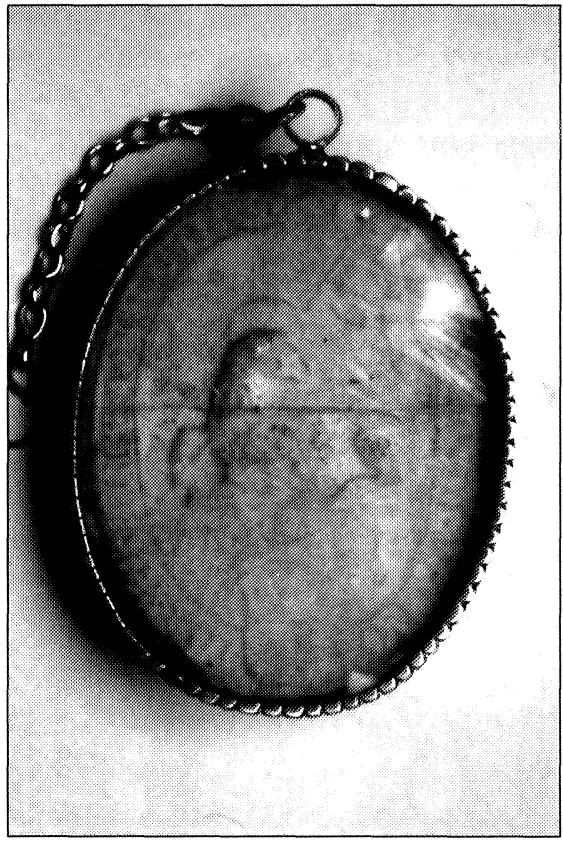

FIG. 6.-Agnusdei de Alejandro VIII (1690). Anverso. N. ${ }^{\circ}$ inv. 11110

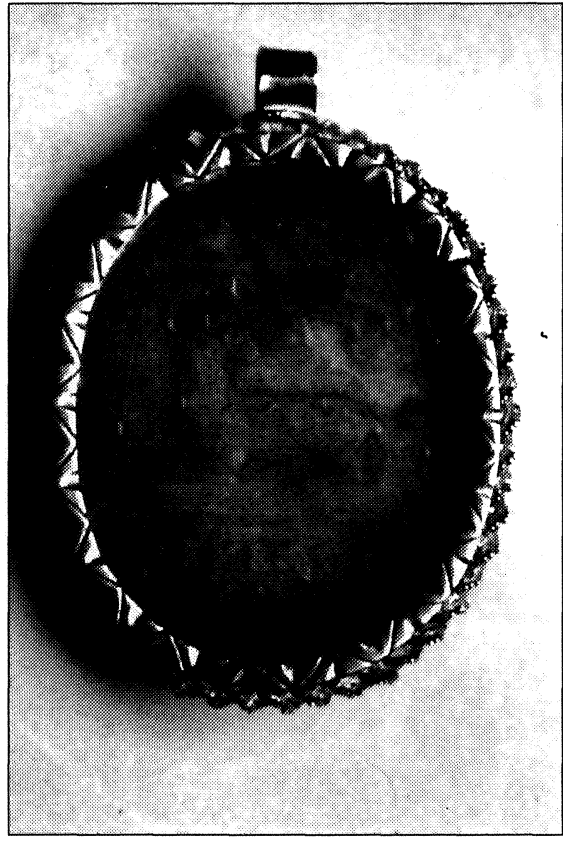

FIG. 7.-Agnusdei de Clemente XI (1714). Anverso. N. ${ }^{\circ}$ inv. 9550.

32 Como ejemplo hay que destacar el magnífico Agnusdei de Pablo V, fechado ca. 1616, publicado por A. CEA GuTIÉRREZ, El tesoro de las reliquias. Colección de la Abadía Cisterciense de Cañas (Logroño: Fundación Caja Rioja, 1999), pp. 156-156, n. ${ }^{\circ} 36$. Se trata de un medallón dorado y policromado con un crucifijo en el reverso. Por su parte, M. EGAN, op. cit., p. 67, publica otro Agnusdei también dorado y policromado fechado en el primer año de pontificado de Gregorio XIII (1572), con la figura de Jesucristo y los símbolos de la Pasión. 
pontificado de Inocencio XIII (1721-1724) corresponden tres Agnusdei, en dos de los cuales se lee 1722 (fig. 8). El de Benedicto XIII (1724-1730) se fecha en el año jubilar 1726.

En el pontificado de Benedicto XIV (1740-1758) se fechan nueve Agnusdei, que presentan una vez más la peculiaridad de estar colocados en un marco, el de mayor tamaño en el centro y los ocho restantes, dispuestos simétricamente junto a cuatro nichos para reliquias, rodeando a aquél (fig. 9). Todos ellos se muestran por el reverso del medallón. Debido a que el cristal de protección y el marco no se han conservado, ambas caras son visibles en todos los casos, permitiendo conocer el ámbito de las preferencias devocionales de este pontífice. Aunque la iconografía del anverso de los Agnus era inamovible, para el reverso cada Papa optaba por una serie de modelos en función de sus devociones. En el caso de Benedicto XIV, en los reversos aparecen Jesucristo, San Antonio de Padua, la Virgen del Carmen, San Benito y Santa Escolástica, San Francisco, San Bernardino, etc.

El Ágnusdei que cierra esta cronología corresponde al pontificado de Pío VI (1775-1799).

Del reparto anual del Agnusdei - con un número de ejemplares necesariamente limitado- se favorecieron personas e instituciones influyen-

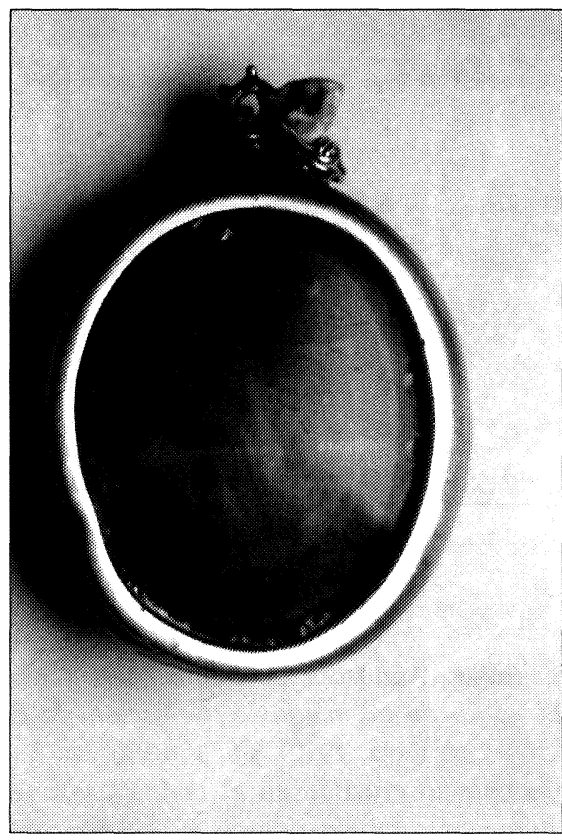

FIG. 8.-Agnusdei de Inocencio XIII (1722). Anverso. N. ${ }^{\circ}$ inv. 12538.

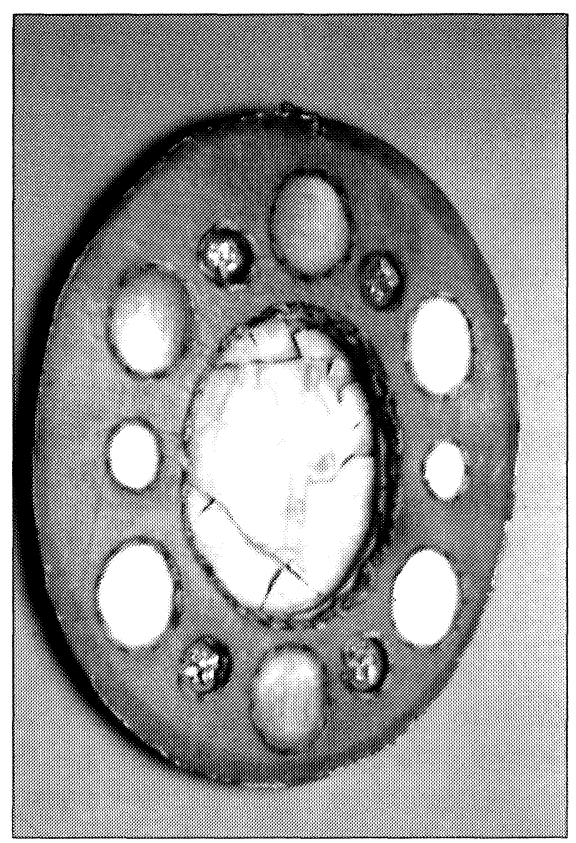

Fig. 9.-Conjunto de Agnusdei de Benedicto XIV. Reverso. N. ${ }^{\circ}$ inv. 13946. 
tes, de manera que la posesión de un medallón era considerada un privilegio. Pero eran muchos los fieles que ansiaban la cera sagrada, y la Iglesia quiso poner los medios necesarios para satisfacer la demanda. Un sistema sencillo para que los beneficios de esta cera llegaran a una mayor cantidad de personas consistía en partir en trozos el Agnusdei, porque, como dicen los texos que se entregaban junto a éste: "Y es de saber, que cualquier parte del Agnus Dei, por pequeña que sea, tiene tanta virtud como todo el entero"; dicho de otro modo: "La parte, aunque pequeña, es tan provechosa como la grande". Por tanto, cualquier fragmento de Agnusdei debe considerarse, a todos los efectos, como un Agnusdei más.

Los pedazos de cera obtenidos a partir de un Agnusdei original multiplicaron de manera considerable el número de fieles beneficiados con sus virtudes, determinando al mismo tiempo, debido a su tamaño minúsculo, las características de un contenedor que ahora debía garantizar su conservación en mayor medida si cabe que en el caso del medallón convencional. Los fragmentos se guardaban en el interior de bolsas o bolsillos de tela (fig. 10), o estuches de formas diversas realizados en madera

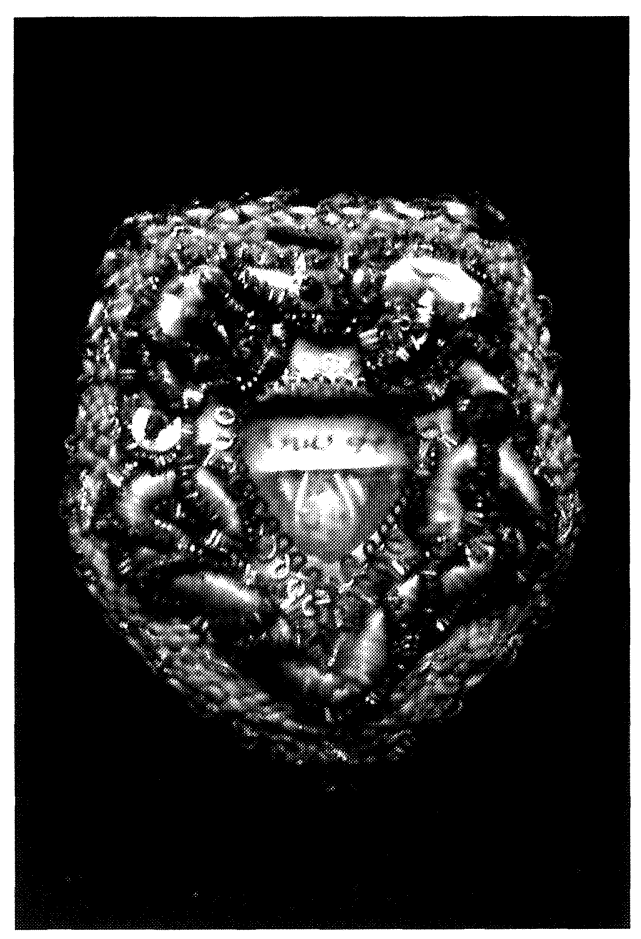

FIG. 10.-Bolsillo en forma de mitra invertida con fragmento de Agnusdei en su interior. Siglo xviII. N. ${ }^{\circ}$ inv. 2337. 
o metal. Cuando las características formales de estos contenedores permitían contemplar la cera bajo un vidrio, ésta aparece siempre convenientemente identificada con la leyenda Agnus Dei o sus variantes Anus Dei, Agnus, Agnus Dei qui, etc.; en la filacteria se especificaba también en ocasiones el nombre del Papa, por ejemplo: Anus Dey de Benedicto XIII, Agnus de Venedi XIII, etc.

Estos contenedores podían ser individuales, es decir, exclusivos para el trozo de cera, o colectivos, en cuyo caso junto al Agnusdei aparecen reliquias varias. Era en los conventos de monjas de clausura donde se realizaba este proceso, siempre con la intención de destacar de manera especial el venerado pedazo, rodeándole de hilo metálico, talcos, lentejuelas, papeles recortados y pintados, virutas de madera, etc.; en resumen, se procedía de igual forma que en el caso de las reliquias. En este contexto es fácil confundir reliquias y Agnusdei, y así ha ocurrido en el caso de los nueve estuches de carácter devocional con trozos de cera que conserva el Museo Nacional de Antropología ${ }^{33}$.

En el estuche podían colocarse incluso varios fragmentos de cera, como sucede en el caso de dos piezas del Museo fechadas a mediados del siglo XVIII ${ }^{34}$. En un relicario de madera en forma de cruz, destinado al culto en una iglesia o un convento, se encuentran cuatro Agnusdei, dos en el lado mayor y otros dos en el menor, y en un relicario de bronce sobredorado, colgante devocional de uso privado, se guardan tres Agnusdei, dos de Inocencio XI (1676-1689) y otro de Benedicto XIII (1724-1730).

Tanto si se trata de Agnusdei completos como de fragmentos, hay que considerar otra cuestión que viene a sumarse a la problemática, ya comentada, de su identificación con reliquias de naturaleza orgánica o textil. Como consecuencia de la necesidad de proteger su frágil integridad física, era común disponer la cera en la parte interna o alma de medallones y estuches, oculta por completo a la observación exterior, de forma que sólo abriendo el contenedor - manipulación que no siempre es recomendable desde el punto de vista de la conservación- es posible conocer la existencia de cera.

La apertura de los estuches, llevada a cabo en el caso de ciertas colecciones por parte de algunos investigadores, ha dado como resultado el hallazgo de fragmentos de Agnusdei en número suficiente como para suponer que no era un hecho esporádico. Así, Gabriel Llompart publicó en 1966 el resultado de su experiencia con un conjunto de bolsillos de

33 Las piezas que presentan fragmentos de Agnusdei son las siguientes: $\mathrm{n} .{ }^{\text {os }}$ inv. 2337, 7398, 7584, 8894, 9119, 9586, 9615, 9845 y 10707.

$34 \quad$ N. ${ }^{\circ}$ inv. 8894 y 9117 respectivamente. 
tela mallorquines, en varios de los cuales aparecieron, pedazos de cera identificados como Agnusdei. Por otra parte, A. Cea Gutiérrez describe así el interior de una pieza de la colección de Caja Zamora: "En el alma, además de algunos naipes - tres tréboles y tres corazones-, envuelto en papel, se halló un agnusdeito fragmentado de cera, del que sólo pudimos leer: DEI, la banderola y la parte superior del cordero" ${ }^{35}$.

\section{El CORDERo PASCUAL Y LA CERA}

No sabemos hasta qué punto la fragmentación del medallón original que constituye el Agnusdei pudo satisfacer el deseo de poseer la cera sagrada. El hecho de que en los inventarios de bienes aparezcan numerosas referencias a los Agnus testimonia sin duda una considerable aceptación de los mismos como objeto devocional por parte de amplios sectores de fieles. Claro que las descripciones de dichos documentos, al incidir de manera especial en el valor económico de unos estuches o colgantes denominados "annus", "anus dey", etc., no permiten asegurar la equivalencia entre unas piezas presentadas con un claro carácter de joyas y los medallones bendecidos en Roma por el Papa.

Por otra parte, la existencia de colgantes devocionales que presentan una iconografía idéntica, e incluso la misma leyenda, que el Agnusdei, invita a pensar que debió existir una especial devoción en torno a la imagen del cordero pascual — derivada probablemente de la arraigada creencia en las virtudes del original Agnusdei de cera- con independencia de la materia prima utilizada en la elaboración del objeto y del aspecto formal adoptado por éste.

Es el caso del colgante del Museo Nacional de Antropología n. ${ }^{\circ}$ inv. 9685, de plata sobredorada, que presenta el cordero pintado bajo vidrio y la leyenda ECCE.AGN.DEI.QVI.TOLT.P., muy similar a una pieza de la colección de la Hispanic Society of America ${ }^{36}$. Al menos dos colgantes del Museo Lázaro Galdiano y el denominado relicario de Agnusdei del Museo de Artes Decorativas también pueden incluirse en este conjunto de objetos que, a través de la iconografía, acabaron adoptando la fórmula nominal correspondiente al medallón de cera original. En la misma línea habría que

35 Gabriel LlomparT, "Dos notas de folklore religioso levantino: Evangelios de bautizo y peregrinos de representación", Revista de Dialectología y Tradiciones Populares, XXII (1966), pp. 7-25, y VV.AA., Fondos etnográficos, artísticos y bibliográficos de la Caja de Zamora. Exposición antológica (Zamora: Caja de Zamora, 1990), p. 42, n. ${ }^{\circ} 65$.

36 P. Muller, op. cit., p. 74. 
situar el colgante de dos cadenas con la figura del cordero pascual de bulto redondo, realizado en oro con diamantes, granates, perlas y esmalte, fechado en el siglo XVII, del Victoria and Albert Museum de Londres ${ }^{37}$.

El punto de partida lo constituye, pues, un modelo iconográfico, el cordero de dios, que pasó a dar nombre a ciertos colgantes devocionales que mantenían dicho modelo, los Agnusdei en los que, sin embargo, la cera no estaba presente. Por extensión, muchos colgantes devocionales desprovistos por completo de la referencia iconográfica del cordero adoptaron el nombre de Agnusdei; de esta manera, en la segunda acepción recogida en el $D R A E$, Agnusdei se convierte en "un relicario que especialmente las mujeres llevaban al cuellon.

De forma paralela a la evolución que tuvo lugar a partir de la imagen del cordero de dios, se produjo un interesante desarrollo del medallón propiamente dicho. Si no perdemos de vista la veneración de que fue objeto la cera así conformada, es lógico suponer que ciertas figuras modeladas en la misma materia situadas en el interior de muchos colgantes devocionales constituyan la lógica evolución del modelo original ${ }^{38}$.

En este contexto deben entenderse las pequeñas esculturas modeladas en cera -entre las que se repite con especial frecuencia la imagen del Niño Jesús-, rodeadas de siemprevivas y talcos de colores y dispuestas bajo vidrio, que se conservan, entre otros, en el Museo Marés de Barcelona, en la colección de Caja España de Zamora, en el Museo Nacional de Artes Decorativas de Madrid (Joyel del Niño Jesús), en la Hispanic Society of America de Nueva York o en el Museo Nacional de Antropología de Madrid (fig. 11).

\section{CONCLUSIONES}

Como consecuencia de su dilatada historia en el tiempo y de su continuo desarrollo formal, el Agnusdei acabó participando de varias cualidades complementarias entre sí. Al carácter devocional inicial, determinado por su singular procedencia, se le añade enseguida el valor de ser un eficaz protector contra el maligno.

Por esta razón, en el Agnusdei se detecta con frecuencia el fenómeno del sincretismo entre el elemento mágico y el aspecto religioso. Ya en 1905, Salillas se hizo eco de estas cuestiones, afirmando:

37 Harold Newman, An Illustrated Dictionary of Jewelry (London: Thames and Hudson, 1994), p. 13.

38 P. Muller, op. cit., p. 74. 
El demonio, en su calidad de enemigo invisible y de utilizador de todo género de influjos para sus tentaciones, es el enemigo por excelencia, y el enemigo tipo, del que derivan de uno ú otro modo todas las personalidades maléficas. Las brujas y brujos no son otra cosa que derivaciones demoníacas: todo consiste en tener pacto con el diablo. De aquí que el embrujamiento no consista, según la terminología popular, en "tener el enemigo", sino en "tener los enemigos". Se dice también "estar espirituados" lo que significa "tener los espítirus malignos" ${ }^{39}$.

Debido a esta caracterización típicamente demoníaca del enemigo, la religión cristiana no ha estado en condiciones de borrar radicalmente las creencias supersticiosas, ni tampoco las prácticas. Lo único que ha conseguido es sustituirlas en todo o en parte.

La confirmación de esta evolución no es exclusiva de España, sino que también es habitual en otros países de nuestro entorno cultural. Así, en Cerdeña los poderes mágico-apotropaicos propios de los amuletos eran

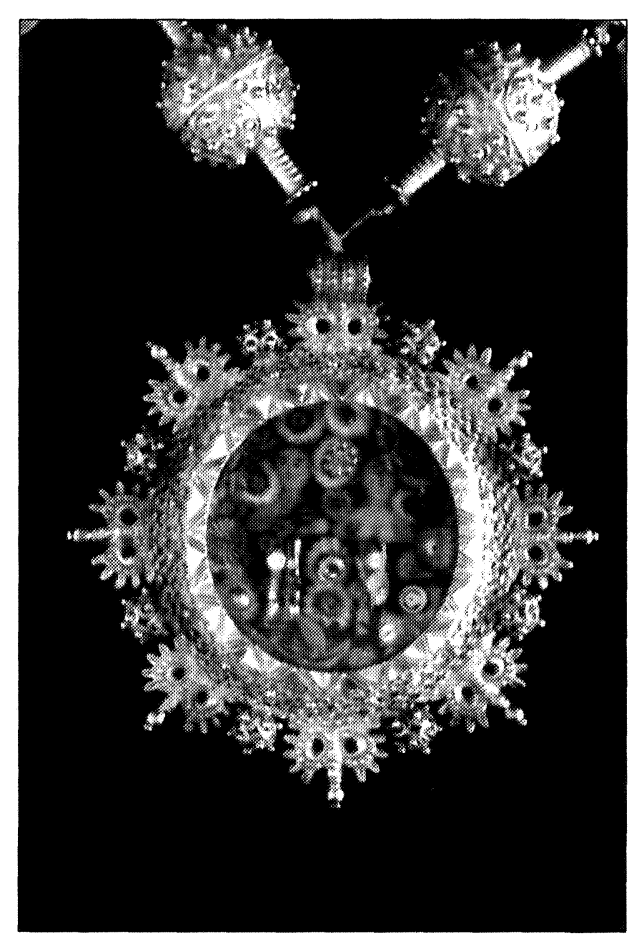

FIG. 11.-Colgante central del collar n. ${ }^{\circ}$ inv. 16580.

39 Rafael SALILLAS, La fascinación en España. Estudio becho con la información promovida por la Sección de Ciencias Morales y Políticas del Ateneo de Madrid (Madrid, 1905), p. 83. 
también atribuidos a los Agnusdei, a las medallas, a las patenas y a los escapularios, objetos que constituyen, en realidad, eficaces defensas contra maleficios, brujerías y ligamentos de hechicería ${ }^{40}$.

Por fin, la necesidad de conservar un objeto frágil dotado de singulares virtudes, colocándolo en el interior de unos estuches de carácter más o menos artístico y de cierto valor económico, acaba convirtiendo el medallón de cera en un objeto precioso, en una joya. Paradójicamente, esta cualidad que ha hecho posible su conservación es al mismo tiempo la que ha terminado prevaleciendo sobre sus valores originales.

De esta forma, el denominado Agnusdei se muestra como un excelente testimonio de la fructífera convivencia que han mantenido las prácticas litúrgicas y devocionales más ortodoxas con ciertos aspectos ligados a la superstición y con los valores artísticos más convencionales.

\section{APÉNDICE}

Con el objeto de facilitar el reconocimiento y la mejor comprensión general de los medallones de cera denominados Agnusdei, se presenta a continuación una relación de los que, además de formar parte de las colecciones del Museo Nacional de Antropología, tienen en común ofrecer al investigador un notable volumen de información derivado de su naturaleza: iconografías, leyendas, pontificados, etc. Este conjunto se ha ordenado a partir del año de consagración de cada uno de ellos o, en su defecto, a partir del pontificado del Papa en cuestión. El orden de exposición de los datos es el siguiente:

Cronología: Año de consagración.

Pontificado: Nombre del Papa y duración de su pontificado.

Anverso: Iconografía, leyenda/s y otras particularidades.

Reverso: Iconografía, leyenda/s y otras particularidades.

Dimensiones.

N. ${ }^{\circ}$ inventario.

\section{0}

Alejandro VIII (1689-1691).

Anverso: cordero nimbado, sentado sobre el libro y sosteniendo el estandarte.

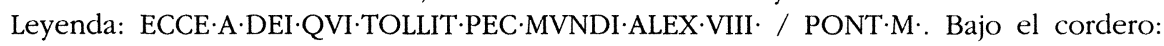
AN.[...]/ 16.90, a ambos lados del escudo papal.

Reverso: Santa Catalina de Siena de tres cuartos, tocada con velo, sosteniendo con las dos manos el Crucifijo; junto a ella, calavera sujetando un libro abierto. Entre la cabeza y el manto, sobrepuesta, pequeña cruz de madera rematada en flecha. Leyen-

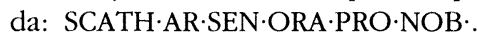

A: $9 \mathrm{~cm}$; An: $7 \mathrm{~cm}$.

N. ${ }^{\circ}$ inv.: 11110.

1714

40 Antonio TAVERA, Il Museo etnografico di Nuoro. La gioelleria (Sassaro: Banco di Sardegna, 1987), p. 178. 
Clemente XI (1700-1721).

Anverso: cordero nimbado, sentado sobre el libro y sosteniendo el estandarte. Leyenda: ECCE·AGN·DEI-QVI-TOL·PECC.MVNDI. Bajo el cordero: CLEMENS·XI / $\mathrm{P} \cdot \mathrm{M} \cdot \mathrm{A} \cdot \mathrm{XIV} / 1714$.

Reverso: busto de Jesucristo a la derecha, barbado y con nimbo. Leyenda: SALVATOR.MVNDI-SALVA-NOS. En exergo: ROMA.

A: $4.5 \mathrm{~cm}$.; An: $3.5 \mathrm{~cm}$.

N..$^{\circ}$ inv.: 9550 .

\section{2}

Inocencio XIII (1721-1724)

Anverso: cordero nimbado, sentado sobre el libro y sosteniendo el estandarte. Leyenda: ECCE·AGN·DEI.QVI.TOL·PEC.MVNDI. En exergo: INNOC·XIII / P.M.A.I / 1722. Reverso: cubierto con una estampa.

A: $5 \mathrm{~cm}$.; An: $4 \mathrm{~cm}$.

N..$^{\circ}$ inv.: 9739 .

1722 Inocencio XIII (1721-1724).

Anverso: cordero nimbado, sentado sobre el libro y sosteniendo el estandarte. Leyenda: ECCE·AGN·DEI.QVI·TOL·PECC.MVNDI. Bajo el cordero: INNOC·XIII / P.M.A.I / 1722 .

Reverso: busto nimbado de San Francisco. Leyenda: S FRANC.ISC.[...]AVER.IT. En exergo: ROMA.

A: $5 \mathrm{~cm}$; An: $4 \mathrm{~cm}$.

N. ${ }^{\circ}$ inv.: 12538 .

\section{1-1724}

Inocencio XIII (1721-1724)

Anverso: cordero nimbado, sentado sobre el libro y sosteniendo el estandarte. Leyenda: ECCE·AGN·DEI·QVI·TOL·PEC·MVNDI. En exergo: INNOC·XIII / [...].

Reverso: San Antonio de Padua con el Niño. Leyenda: S-ANTONIO DE PADVA.CONFES. En exergo: INNOC.XIII / P.M.

A: $4.5 \mathrm{~cm}$; An: $4 \mathrm{~cm}$.

N..$^{\circ}$ inv.: 11088 .

\section{6}

Benedicto XIII (1724-1730)

Anverso: cordero nimbado, sentado sobre el libro y sosteniendo el estandarte. Leyenda: ilegible. En exergo: BENED·XIII / P.M.A.IVB / 1726.

Reverso: Cubierto con papel y seda de colores, que enmarcan varias reliquias.

D: $4.5 \mathrm{~cm}$.

N. ${ }^{\circ}$ inv.: 9684 .

\section{0-1758}

Benedicto XIV (1740-1758)

Anverso: cordero nimbado, sentado sobre el libro y sosteniendo el estandarte. Leyenda: ECCE·AGN·DEI-QVI·TOL·PECC.MVNDI. En exergo: BENED·XIV.

Reverso: San Antonio de Padua con el Niño. Leyenda: S-ANTONIO-DE PADVA.CONFES. En exergo: BENE'XIV / P.M.

A: $5 \mathrm{~cm}$.; An: $3.5 \mathrm{~cm}$.

N..$^{\circ}$ inv.: 13946.

1740-1758 
Benedicto XIV (1740-1758)

Anverso: cordero nimbado, sentado sobre el libro y sosteniendo el estandarte. Leyenda: ECCE·AGN·DEI·QVI·TOL·PECC·MVNDI. En exergo: BENED·XIV.

Reverso: figura masculina nimbada con hábito y báculo, junto a un libro abierto.

A. $3 \mathrm{~cm}$; An: $2.5 \mathrm{~cm}$.

N. ${ }^{\circ}$ inv.: 13946.

\section{0-1758}

Benedicto XIV (1740-1758)

Anverso: cordero nimbado, sentado sobre el libro y sosteniendo el estandarte. Leyenda: ECCE·AGN·DEI·QVI·TOL·PECC.MVNDI. En exergo: BENED·XIV.

Reverso: Virgen del Carmen con el Niño. Leyenda: DECOR / CARMELIT.

A: $5 \mathrm{~cm}$; An: $4 \mathrm{~cm}$.

N. ${ }^{\circ}$ inv.: 13946.

\section{0-1758}

Benedicto XIV (1740-1758)

Anverso: cordero nimbado, sentado sobre el libro y sosteniendo el estandarte. Leyenda: ECCE·AGN·DEI·QVI·TOL·PECC.MVNDI. En exergo: BENED·XIV.

Reverso: dos figuras de pie, una masculina y otra femenina, a ambos lados de un sol. Leyenda ilegible. En exergo: S.A.LOY [...] S.STANISLAO-

A: $4.5 \mathrm{~cm}$; An: $4 \mathrm{~cm}$.

N. ${ }^{\circ}$ inv.: 13946.

\section{1}

Benedicto XIV (1740-1758)

Anverso: cordero nimbado, sentado sobre el libro y sosteniendo el estandarte. Leyenda: ECCE·AGN·DEI·QVI·TOL·PECC.MVNDI. En exergo: BENED·XIV / P·M·ANN·I.

Reverso: dos figuras de pie, una masculina y otra femenina, ambas nimbadas, sosteniendo báculo y libro abierto. Leyenda: S·BENEDICTUS·S·SCOLAS. En exergo: BENED $\cdot X I V$ / PON $\cdot \mathrm{M} \cdot$

A: $4.5 \mathrm{~cm}$; An: $4 \mathrm{~cm}$.

N. ${ }^{\circ}$ inv.: 13946.

1740-1758

Benedicto XIV (1740-1758)

Anverso: cordero nimbado, sentado sobre el libro y sosteniendo el estandarte. Leyenda: ECCE·AGN·DEI·QVI·TOL·PECC·MVNDI. En exergo: BENED·XIV.

Reverso: busto masculino a la derecha. Leyenda ilegible.

A: $2.8 \mathrm{~cm}$; An: $2.5 \mathrm{~cm}$.

N. ${ }^{\circ}$ inv.: 13946.

\section{1}

Benedicto XIV (1740-1758)

Anverso: cordero nimbado, sentado sobre el libro y sosteniendo el estandarte. Leyenda: ECCE·AGN·DEI·QVI·TOL·PECC.MVNDI. En exergo: BENED·XIV /P.M·ANN·I.

Reverso: San Francisco de Asís, de tres cuartos, con un libro delante. Leyenda: S.FRANC [...]. En exergo: BENED·XIV / P.M·.

A: $4.8 \mathrm{~cm}$; An: $3.8 \mathrm{~cm}$.

N. ${ }^{\circ}$ inv.: 13946.

1741 


\section{Benedicto XIV (1740-1758)}

Anverso: cordero nimbado, sentado sobre el libro y sosteniendo el estandarte. Leyenda: ECCE·AGN·DEI.QVI·TOL.P.MVN·BEN·XIV / PON.MAX. En exergo, a ambos lados del escudo papal: ANN·I / 17.41.

Reverso: San Bernardino, sosteniendo un libro en la mano izquierda. Leyenda: $S \cdot B E R N A R \cdot D I N O S \cdot D E \cdot S E N I S$. En exergo: BEND·XIV / P.M.

A: $15.5 \mathrm{~cm}$.; An: $11.5 \mathrm{~cm}$.

N. ${ }^{\circ}$ inv.: 13946

1779

Pío VI (1775-1799)

Anverso: cordero nimbado, sentado sobre el libro y sosteniendo el estandarte. Leyenda: ECCE·AGNVS·DEI-QVI-TOLLIT'PECCATA.MVNDI. En exergo, a ambos lados del escudo papal: PIVS.VI / P.M.A.IVB / 17.79.

Reverso: San Agustín, sosteniendo un libro abierto en su mano derecha; está arrodillado junto al Niño, que sostiene su báculo. Leyenda: SAN.PATER·AVGVST / INVS·D·EC.

A: $8 \mathrm{~cm}$.; An: $7 \mathrm{~cm}$.

N. ${ }^{\circ}$ inv.: 8949.

A través de la investigación de fuentes literarias, la autora estudia la cera en cuanto materia sagrada y especialmente el Agnusdei — sello de cera estampado con la figura del Cordero de Dios que supone un destacado aspecto de la devoción cristiana-, su iconografía y sus aspectos sociales y simbólicos. En el desarrollo del tema, el estudio de las fuentes escritas se contrasta con el análisis de piezas conservadas en el Museo Nacional de Antropología de Madrid y en otros museos e instituciones.

Following a research on literature the author discusses the wax as holy material, and particularly the Agnusdei -wax seal stamped with the image of the Lamb of God- as an important aspect of Christian devotion, its iconography and its social and simbolic aspects. In her discussion, the study of the written material appears in contrast to the analysis of pieces owned in Museo Nacional de Antropología, Madrid, and collections of other museums and institutions. 